\title{
Facile Synthesis of Calcium Carbonate Nanoparticles from Cockle Shells
}

\section{Kh. Nurul Islam, ${ }^{1}$ A. B. Z. Zuki, ${ }^{1,2}$ M. E. Ali, ${ }^{3}$ Mohd Zobir Bin Hussein, ${ }^{4}$ M. M. Noordin, ${ }^{5}$ M. Y. Loqman, ${ }^{6}$ H. Wahid, ${ }^{4}$ M. A. Hakim, ${ }^{7}$ and Sharifa Bee Abd Hamid ${ }^{3}$}

\author{
${ }^{1}$ Laboratory of Histology, Department of Preclinical Sciences, Faculty of Veterinary Medicine, Universiti Putra Malaysia, \\ Selangor, 43400 Serdang, Malaysia \\ ${ }^{2}$ Institute of Bioscience, University Putra Malaysia, Selangor, 43400 Serdang, Malaysia \\ ${ }^{3}$ Nanotechnology and Catalysis Research Center, University of Malaya, 50603 Kuala Lumpur, Malaysia \\ ${ }^{4}$ Laboratory of Nanomaterials, Department of Chemistry, Faculty of Science, Universiti Putra Malaysia, \\ Selangor, 43400 Serdang, Malaysia \\ ${ }^{5}$ Laboratory of Pathology, Department of Veterinary Pathology and Microbiology, Faculty of Veterinary Medicine, \\ Universiti Putra Malaysia, Selangor, 43400 Serdang, Malaysia \\ ${ }^{6}$ Department of Clinical Veterinary Studies, Faculty of Veterinary Medicine, Universiti Putra Malaysia, Selangor, \\ 43400 Serdang, Malaysia \\ ${ }^{7}$ Institute of Tropical Agriculture, Universiti Putra Malaysia, Selangor, 43400 Serdang, Malaysia
}

Correspondence should be addressed to A. B.Z.Zuki, zuki@vet.upm.edu.my

Received 14 May 2012; Revised 13 July 2012; Accepted 5 August 2012

Academic Editor: Jiu-Ju Feng

Copyright ( $\odot 2012 \mathrm{Kh}$. Nurul Islam et al. This is an open access article distributed under the Creative Commons Attribution License, which permits unrestricted use, distribution, and reproduction in any medium, provided the original work is properly cited.

A simple and low-cost method for the synthesis of calcium carbonate nanoparticles from cockle shells was described. Polymorphically, the synthesized nanoparticles were aragonites which are biocompatible and thus frequently used in the repair of fractured bone and development of advanced drug delivery systems, tissue scaffolds and anticarcinogenic drugs. The rod-shaped and pure aragonite particles of $30 \pm 5 \mathrm{~nm}$ in diameter were reproducibly synthesized when micron-sized cockle shells powders were mechanically stirred for $90 \mathrm{~min}$ at room temperature in presence of a nontoxic and nonhazardous biomineralization catalyst, dodecyl dimethyl betaine (BS-12). The findings were verified using a combination of analytical techniques such as variable pressure scanning electron microscopy (VPSEM), transmission electron microscopy (TEM), Fourier transmission infrared spectroscopy (FT-IR), X-ray diffraction spectroscopy (XRD), and energy dispersive X-ray analyser (EDX). The reproducibility and low cost of the method suggested that it could be used in industry for the large scale synthesis of aragonite nanoparticles from cockle shells, a low cost and easily available natural resource.

\section{Introduction}

Calcium carbonate $\left(\mathrm{CaCO}_{3}\right)$, which is one of the most abundant minerals in nature, exists in three polymorphs: calcite, aragonite, and vaterite [1]. Among these three polymorphs, aragonite has got enormous research attention because of its biocompatible properties [2-5]. It is denser than calcite and can be integrated, resolved, and replaced by bone $[4,6]$. Aragonite is also a potential biomaterial for the development of anticancer drugs, advanced drug delivery systems [7], and scaffolds for bone repair and tissue engineering [4]. Because of the presence of many attractive and useful properties in aragonite polymorphs, enormous research attention has been paid in the development of methodology for the controlled and facile synthesis of aragonite nanoparticles (ANPs) with convenient sizes and shapes $[2,3,5]$. Two fundamental routes for the bottom up synthesize of ANPs are documented: (1) the solution route in which aqueous $\mathrm{CaCl}_{2}$ and 
$\left(\mathrm{NH}_{4}\right)_{2} \mathrm{CO}_{3}$ or $\mathrm{CaCl}_{2}$ and $\mathrm{Na}_{2} \mathrm{CO}_{3}$ or $\mathrm{Ca}\left(\mathrm{NO}_{3}\right)_{2}$ and $\mathrm{Na}_{2} \mathrm{CO}_{3}$ $[2,3,8-12]$ are combined in equimolar ratios through a double decomposition reaction and (2) the carbonation route in which $\mathrm{CO}_{2}$ gas is bubbled through an aqueous slurry of $\mathrm{Ca}(\mathrm{OH})_{2}$ at a specified temperature in presence of organic substrates such as polyacrylamide [5]. However, none of these routes can produce pure aragonite nanoparticles of suitable sizes and shapes. They are often mixed with calcite [3] or calcite and vaterite [2] and thus may not be suitable for a specialized biomedical application. Although carbonation methods are viewed to be eco-environmentally friendly, they need stringent temperature control, purified raw materials, and laborious gas $\left(\mathrm{CO}_{2}\right.$ or mixture of $\mathrm{CO}_{2}$ and $\left.\mathrm{N}_{2}\right)$ bubbling steps which incur additional cost, time, and skills $[5,13]$. These methods also add organic impurities to the final products [13].

The synthesis of ANPs from its natural reservoirs such as cockle shells or sea shells using a top-down approach is greatly promising. In our last report [4], we have shown that cockle shells and its powders are rich and naturally purified source of aragonite polymorphs of calcium carbonate. In this paper, we developed an easy-to-perform, environmentally friendly, and low-cost method that involved a simple mechanical stirring of cockle shell powder in presence of BS12 as a biomineralization catalyst. The method synthesized the smallest size ANPs so far reported in literatures [25]. The beauty of the method was that it did not add any impurities to the final products but produced very smallsized rod-shaped ANPs in a reproducible fashion, a criteria which is strongly desired in industrial synthesis.

\section{Experimental}

Approximately $250 \mathrm{gm}$ of cockle shells (Anadara granosa) were washed and scrubbed to remove dirt, boiled for 10 minutes and then cooled at room temperature. The shells were then washed thoroughly with distilled water and dried in an oven (Memmert UM500, Germany) for seven days at $50^{\circ} \mathrm{C}$. The cockle shells were finely grounded using a blender (Blendor, HCB 550, USA). The powders were sieved using a stainless laboratory test sieve with an aperture size of $90 \mu \mathrm{m}$ (Endecott Ltd., London, England) to obtain micronsized (10-90 $\mu \mathrm{m}$ in diameter) powders [4]. Dodecyl dimethyl betaine $\left(\mathrm{RN}+\left(\mathrm{CH}_{3}\right)_{2} \mathrm{CH}_{2} \mathrm{COO}-\right)(\mathrm{BS}-12)$ was obtained from Sigma-Aldrich (Steinheim, Germany). The water used was HPLC-grade of resistance $>18 \mathrm{M} \Omega$ obtained from a MilliRO6 plus Milli-Q-Water System (Organex).

For the synthesis of calcium carbonate nanoparticles, 5 grams of micron-sized cockle shells powders were taken into two separate $250-\mathrm{mL}$ conical flasks. To each of the conical flasks, $50 \mathrm{~mL}$ distilled water was added to form a slurry. Two millilitres of BS-12 (as obtained from Sigma-Aldrich) was added into the second flask. The sample of the first conical flask was used as a control. After the addition of BS12 , the mixtures were vigorously stirred for $90 \mathrm{~min}$ at room temperature using a mechanical hot plate stirrer at the rate of $1000 \mathrm{rpm}$. The obtained samples were separated from the mother liquid using a double ring filter paper of size $18.0 \mathrm{~cm}$ (Filtres Fioroni, China). The final products were dried for 1 day in an oven (Memmert UM500) at $100^{\circ} \mathrm{C}$ and packed in a polyethylene plastic bag (JP Packaging) for further use.

The surface morphologies of the produced nanoparticles were studied using a variable pressure scanning electron microscope (VPSEM, LEO 1455, Germany) after coating the powder with gold. The elemental analyses were performed using an energy dispersive X-ray analyser (EDX, model 7353, England), directly connected to the VPSEM. The crystal shapes and sizes were determined using a TEM (Hitachi H7100 , Japan). For TEM study, the produced nanoparticles powder of cockle shells were mixed with absolute alcohol under sonication for $30 \mathrm{~min}$, and the colloidal solution was dropped on to a carbon-covered copper grid, placed on a filter paper, and dried at room temperature for $1 \mathrm{~h}$. The purity and crystalline properties of the powders were investigated by an X-ray powder diffractometer (Shimadzu XRD-6000, Japan) operated at $\mathrm{CuK}_{\alpha}(\lambda=1.540562 \AA)$. The chemical analyses were done using a Fourier transform infrared (FT-IR) spectrophotometer (Model 100, Perkin Elmer, 710 Bridgeport Avenue, Shelton, CI USA) over a range of 280 to $4000 \mathrm{~cm}^{-1}$ at a resolution of $2 \mathrm{~cm}^{-1}$ and at scan speed of $64 / \mathrm{s}$.

\section{Results and Discussion}

The surface morphologies as obtained from VPSEM cockle shells powder before (Figure 1(a)) and after adding BS-12 (Figure 1(b)) are shown in Figure 1. While the rod-shaped aragonite crystals clearly appeared in the cockle shells powder before adding BS-12 (Figure 1(a)), the larger clumps of smaller and agglomerated calcium carbonate crystals were observed after treatment with BS-12 (Figure 1(b)). The SEM studies thus suggested that BS- 12 probably catalyzed the breakdown of larger particles into the smaller ones through the enhancement of inter particle adhesiveness.

To visualize the calcium carbonate particles more clearly, transmission electron micrographs were studied. The TEM images of cockle shells powder before (Figure 2(a)) and after adding $2 \mathrm{~mL}$ of BS-12 (Figure 2(b)) are shown in Figure 2. While the micron-sized rod-like aragonite crystals of diameter 10-90 $\mu \mathrm{m}$ were observed in the cockle shells powders without addition of any organic surfactant or catalyst (Figure 2(a)), the rod-shaped aragonite crystals of diameter $30 \pm 5 \mathrm{~nm}$ clearly appeared in the presence of $2 \mathrm{~mL}$ of BS-12 (Figure 2(b)). A number of previous studies indicated the formation of rod-like aragonite crystals in presence of polyacrylamide [5] or in absence of any organic substrates such as polyacrylamide or BS-12 [3]. However, none of these studies obtained pure aragonite crystals of homogeneous sizes and shapes. In most of the cases, the aragonite crystals were obtained as a mixture of calcite and aragonite [3,5] or calcite, vaterite, and aragonite [2]. For the first time, we prepared rod-shaped aragonite crystals of the smallest and homogeneous sizes and shapes from a low cost and available natural resource such as cockle shell, using a top-down approach in the presence of BS-12. BS12 is extensively reported in the bottom-up approach [13] where it acts as a surfactant to control the nucleation and growth pattern of the calcite particles. However, the method 


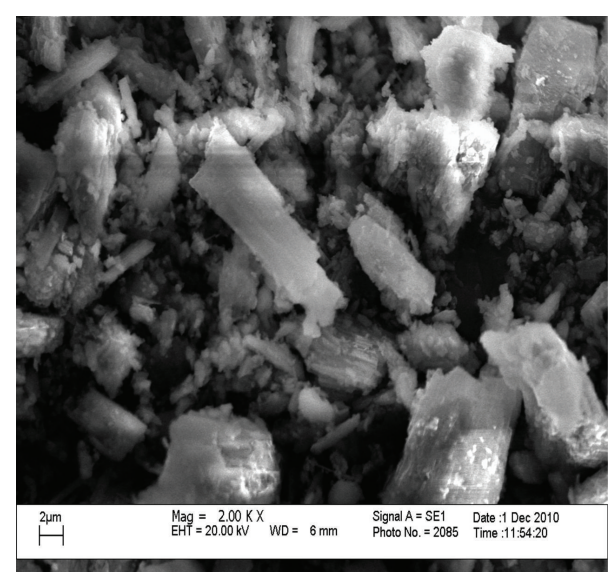

(a)

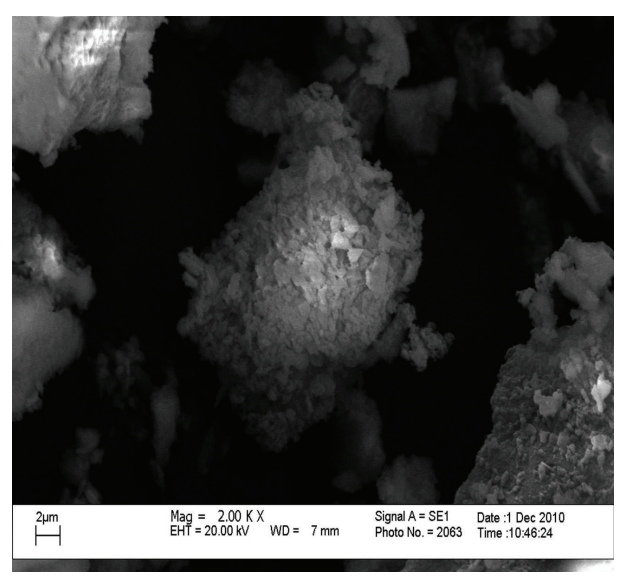

(b)

FIGURE 1: SEM micrograph of cockle shells powders before (a) and after (b) the addition of BS-12. The crystals of cockle shells powders were white, larger, rod-shaped, and separated in the absence of BS-12, whereas the crystals were smaller sized, agglomerated, and clumped together in the presence of BS-12.

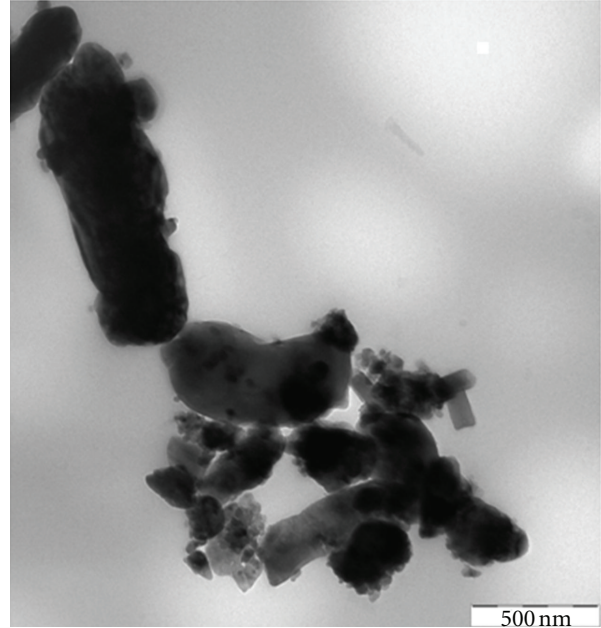

(a)

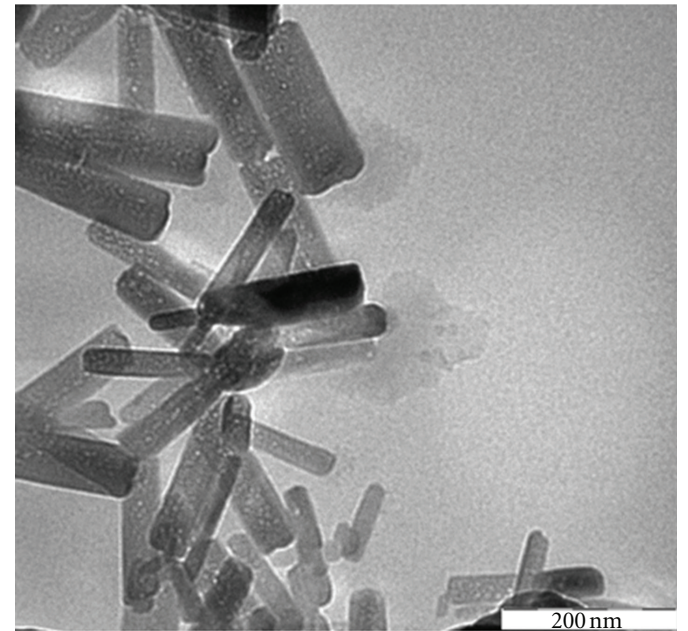

(b)

FIGURE 2: TEM image of cockle shells powders before (a) and after (b) the addition of BS-12. While the micron-sized rough rod-like crystals were observed before adding any catalyst (a), the clear nanosized rod-like crystals were synthesized after adding BS-12 as a catalyst (b).

adds some BS-12 impurities in the final products which may not be suitable for biological applications [13]. However, in this study, we have not observed any BS-12 as impurities in the final aragonite particles. Here, BS-12 probably acted as a catalyst to loosen the bundles of rod-shaped aragonite crystals that are present as a large bundles in the original cockle shells as well as in its powder form.

The FT-IR spectra of cockle shells powders before (Figure $3(\mathrm{a})$ ) and after the addition of $2 \mathrm{~mL}$ of $\mathrm{BS}-12$ (Figure 3(b)) are demonstrated in Figure 3. Prominent absorption peaks of carbonate appeared at $1455 \mathrm{~cm}^{-1}$ in the cockle shells powders in all conditions ((Figure 3(a)) and (Figure 3(b))). No positional shift of this peak was observed before (Figure 3(a)) and after adding BS-12 (Figure 3(b)).
This peak was attributed to the alkyl group which is present in the aragonite polymorphs [4]. Two other peaks appeared at $1794 \mathrm{~cm}^{-1}$ and $2520 \mathrm{~cm}^{-1}$ were referred to the amide and carboxylic stretching vibration [4]. The characteristic peaks, which represent $\mathrm{CO}_{3}{ }^{2-}$ of aragonite, were observed at $1082 \mathrm{~cm}^{-1}$ and $857 \mathrm{~cm}^{-1}$. No positional shift of these peaks was seen before and after addition of BS-12. The peaks defining the $\mathrm{CO}_{3}{ }^{2-}$ of aragonite appeared at 1082 and $857 \mathrm{~cm}^{-1}[4,11]$. Wang et al. [13] obtained two peaks at 2875 and $2993 \mathrm{~cm}^{-1}$ in calcite nanoparticles synthesised via carbonation method in the presence of BS-12 as an organic surfactant. These peaks were assigned to the residual BS12 , embedded on the particle surfaces. However, such a peak that can demonstrate the presence or contamination 
TABLE 1: EDX profiles of cockle shells powders before (a) and after (b) the addition of $2 \mathrm{~mL}$ BS-12. No significant change in the presence of BS-12.

\begin{tabular}{|c|c|c|c|c|c|c|c|}
\hline Spectrum & $\mathrm{C}$ & $\mathrm{O}$ & $\mathrm{Al}$ & $\mathrm{Ca}$ & $\mathrm{Cu}$ & $\mathrm{Te}$ & Total \\
\hline \multicolumn{8}{|l|}{ Without BS-12 (a) } \\
\hline Spectrum 1 & 16.39 & 30.15 & 0.61 & 50.12 & 1.4 & 1.33 & 100 \\
\hline Spectrum 2 & 15.66 & 28.8 & 0.47 & 52.38 & 2.3 & 0.39 & 100 \\
\hline Spectrum 3 & 30.93 & 27.71 & 1.69 & 32.76 & 4.96 & 1.95 & 100 \\
\hline Mean & 20.99 & 28.88 & 0.92 & 45.08 & 2.88 & 1.22 & 100 \\
\hline Std. deviation & 8.61 & 1.22 & 0.66 & 10.73 & 1.85 & 0.78 & \\
\hline Max & 30.93 & 30.15 & 1.69 & 52.38 & 4.96 & 1.95 & \\
\hline Min & 15.66 & 27.71 & 0.47 & 32.76 & 1.4 & 0.39 & \\
\hline \multicolumn{8}{|l|}{ With BS-12 (b) } \\
\hline Spectrum 1 & 16.10 & 30.26 & 0.67 & 50.27 & 1.35 & 1.35 & 100 \\
\hline Spectrum 2 & 15.65 & 28.79 & 0.47 & 52.46 & 2.29 & 0.34 & 100 \\
\hline Spectrum 3 & 30.93 & 27.71 & 1.69 & 32.76 & 4.91 & 2.00 & 100 \\
\hline Mean & 20.89 & 28.92 & 0.94 & 45.16 & 2.85 & 1.23 & 100 \\
\hline Std. deviation & 8.70 & 1.27 & 0.64 & 10.78 & 1.85 & 0.81 & \\
\hline Max & 30.93 & 30.26 & 1.69 & 52.46 & 4.91 & 2.00 & \\
\hline Min & 15.65 & 27.71 & 0.47 & 32.76 & 1.35 & 0.34 & \\
\hline
\end{tabular}

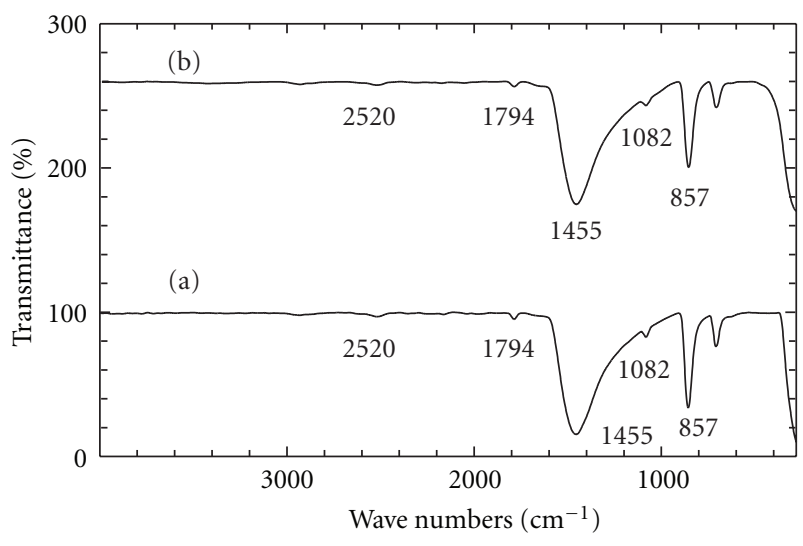

FIGURE 3: FT-IR spectra of cockle shells powders before (a) and after (b) the addition of BS-12. The characteristics absorption peaks of aragonite polymorph were observed both in the absence and presence of BS-12 ((a) and (b)).

of BS-12 was totally absent in the FT-IR spectra of the synthesised aragonite nanoparticles, suggesting that ANPs were synthesised without any additional impurities.

The XRD patterns of cockle shells powders before (Figure $4(\mathrm{a})$ ) and after adding $2 \mathrm{~mL}$ of BS-12 (Figure $4(\mathrm{~b})$ ) are demonstrated in Figure 4. The XRD patterns of cockle shells powders (Figure 4(a)) completely matched with the aragonite phase (JCPDS file no. 00-003-0425). The reflection patterns of cockle shells powders (Figure 4(b)) were characteristic of calcium carbonate in the aragonite phase (JCPDS no. 00-001-0628). No additional influence of BS12 was found in any of these XRD profiles. The XRD patterns of cockle shells powders did not show any peaks of mixed polymorphs such as calcite and aragonite $[3,5]$ or calcite, aragonite, and vaterite [2], demonstrating that pure crystalline aragonite nanoparticles were synthesised in the presence of BS-12 which most likely acted as a biomineralization catalyst.

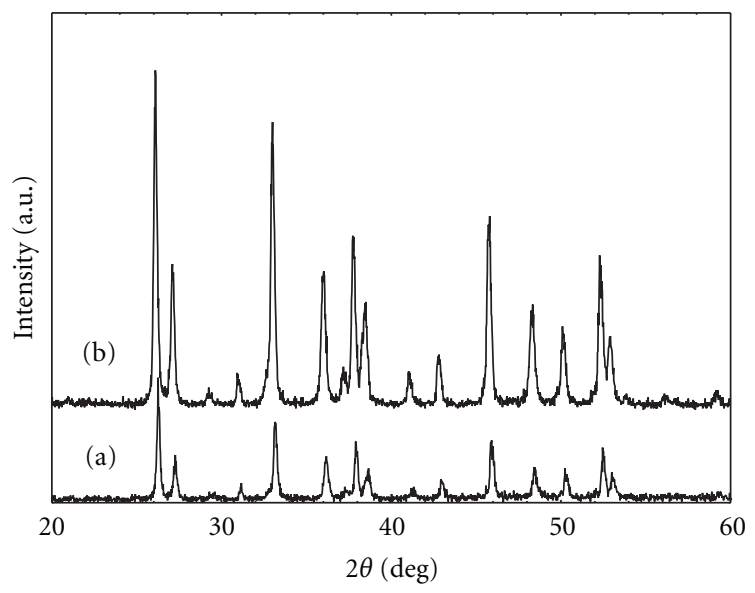

FIGURE 4: XRD patterns of cockle shells powders before (a) and after (b) the addition of BS-12. The aragonite phase appeared in both XRD patterns.

The elemental compositions of the cockle shells powders before and after adding $2 \mathrm{~mL}$ of BS-12 are shown in Table 1. While the cockle shells powders in the absence of BS-12 contained $20.99 \%$ carbon, $28.88 \%$ oxygen, $0.92 \%$ aluminium, $45.08 \%$ calcium, $2.88 \%$ copper, and $1.22 \%$ tellurium [4], the cockle shells powders in presence of $2 \mathrm{~mL}$ of BS-12 contains $20.89 \%$ carbon, $28.92 \%$ oxygen, $0.94 \%$ aluminium, $45.16 \%$ calcium, $2.85 \%$ copper, and $1.23 \%$ tellurium. No significant change in the elemental compositions of the obtained cockle shells nanoparticles were found after the addition of BS-12, reflecting the catalytic role of BS-12 in the breakdown of larger bundles of aragonite rods into the smaller or singular ones.

\section{Conclusion}

A simple, low-cost, and environmentally friendly method for the synthesis of calcium carbonate nanoparticles (aragonite) 
from a low-cost and abundant natural resource, cockle shell, was developed. The method was a top-down approach which involved minimum procedural steps and did not need any stringent temperature management, expensive and hazardous chemicals or any carbonation step of expensive and time consuming gas bubbling. It was simply a mechanical grinding process using very simple, easily available, and low-cost instrument in the presence of a biomineralization catalyst, dodecyl dimethyl betaine. The method produces very small-sized excellent rod-shaped and pure aragonite nanoparticles with an average diameter of $30 \pm 5 \mathrm{~nm}$ in a reproducible manner without any additional impurities. The method has a great potential to be used in industry for largescale synthesis of aragonite nanoparticles for biomedical applications.

\section{Acknowledgment}

The authors gratefully acknowledge the financial support from the Fundamental Research Grand Scheme of Malaysia (FRGS).

\section{References}

[1] H. Bala, W. Fu, J. Zhao et al., "Preparation of $\mathrm{BaSO}_{4}$ nanoparticles with self-dispersing properties," Colloids and Surfaces A, vol. 252, no. 2-3, pp. 129-134, 2005.

[2] J. Chen and L. Xiang, "Controllable synthesis of calcium carbonate polymorphs at different temperatures," Powder Technology, vol. 189, pp. 64-69, 2009.

[3] F. Guo, Y. Li, H. Xu, G. Zhao, and X. He, "Size-controllable synthesis of calcium carbonate nanoparticles using aqueous foam films as templates," Materials Letters, vol. 61, no. 27, pp. 4937-4939, 2007.

[4] K. N. Islam, A. B. Z. Zuki, M. M. Noordin, M. Z. B. Hussein, N. S. S. B. A. Rahman, and M. E. Ali, "Characterisation of calcium carbonate and its polymorphs from cockle shells (Anadara granosa)," Power Technology, vol. 213, no. 1-3, pp. 188-191, 2011.

[5] C. Wang, J. Zhao, X. Zhao, H. Bala, and Z. Wang, "Synthesis of nanosized calcium carbonate (aragonite) via a polyacrylamide inducing process," Powder Technology, vol. 163, no. 3, pp. 134138,2006

[6] S. I. Stupp and P. V. Braun, "Molecular manipulation of microstructures: biomaterials, ceramics, and semiconductors," Science, vol. 277, no. 5330, pp. 1242-1248, 1997.

[7] Z. P. Xu, Q. H. Zeng, G. Q. Lu, and A. B. Yu, "Inorganic nanoparticles as carriers for efficient cellular delivery," Chemical Engineering Science, vol. 61, no. 3, pp. 1027-1040, 2006.

[8] H. Kawaguchi, H. Hirai, K. Sakai et al., "Crystallization of inorganic compounds in polymer solutions. Part I: control of shape and form of calcium carbonate," Colloid \& Polymer Science, vol. 270, no. 12, pp. 1176-1181, 1992.

[9] N. Wada, S. Suda, K. Kanamura, and T. Umegaki, "Formation of thin calcium carbonate films with aragonite and vaterite forms coexisting with polyacrylic acids and chitosan membranes," Journal of Colloid and Interface Science, vol. 279, no. 1, pp. 167-174, 2004.

[10] A. M. Belcher, X. H. Wu, R. J. Christensen, P. K. Hansma, G. D. Stucky, and D. E. Morse, "Control of crystal phase switching and orientation by soluble mollusc-shell proteins," Nature, vol. 381, no. 6577, pp. 56-58, 1996.
[11] C. S. Choi and Y. W. Kim, "A study of the correlation between organic matrices and nanocomposite materials in oyster shell formation," Biomaterials, vol. 21, no. 3, pp. 213-222, 2000.

[12] R. Lakshminarayanan, S. Valiyaveettil, and G. L. Loy, "Selective nucleation of calcium carbonate polymorphs: role of surface functionalization and poly(vinyl alcohol) additive," Crystal Growth and Design, vol. 3, no. 6, pp. 953-958, 2003.

[13] C. Wang, Y. Liu, H. Bala et al., "Facile preparation of $\mathrm{CaCO}_{3}$ nanoparticles with self-dispersing properties in the presence of dodecyl dimethyl betaine," Colloids and Surfaces A, vol. 297, no. 1-3, pp. 179-182, 2007. 

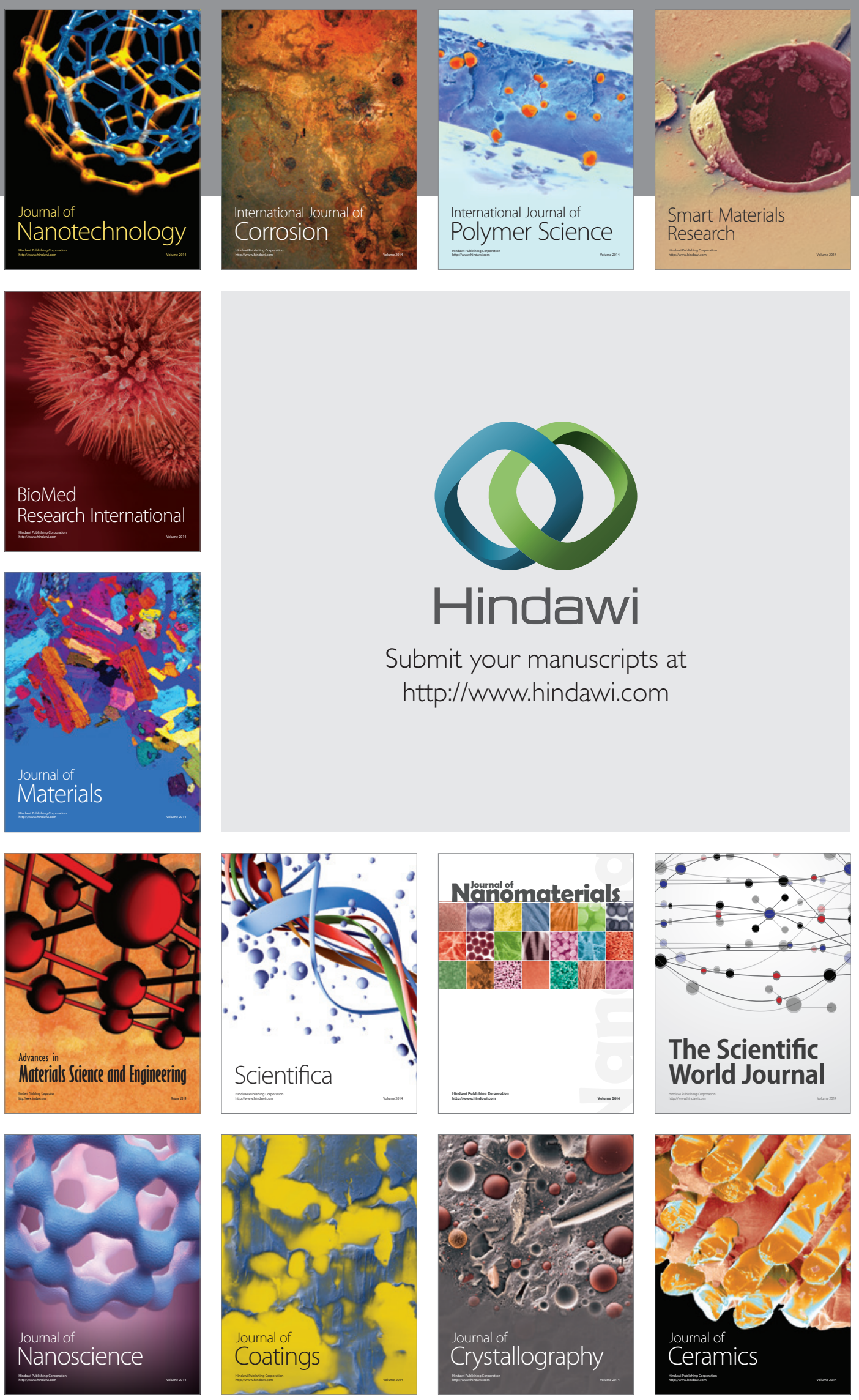

The Scientific World Journal

Submit your manuscripts at

http://www.hindawi.com

\section{World Journal}

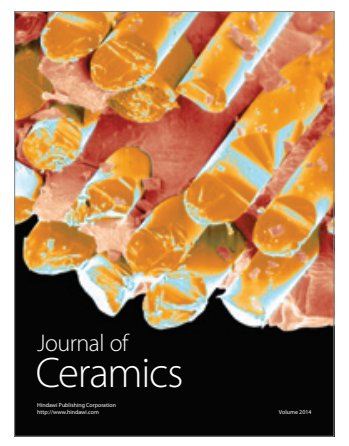

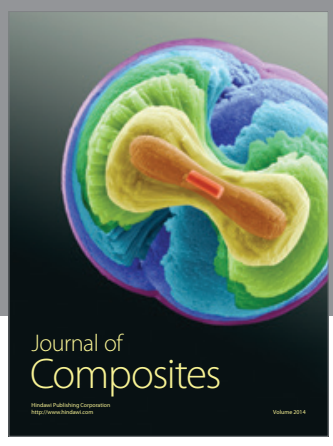
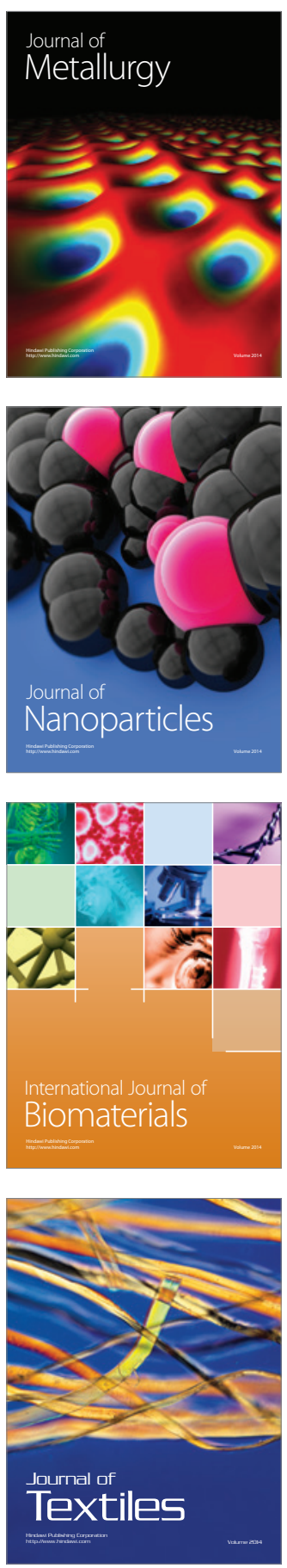